\title{
EFFECT OF ALPHA LIPOIC ACID IN TREATMENT OF TYPE 2 DIABETES
}

\author{
PRIYAMBADA PANDA ${ }^{1 *}$, SITANSU KUMAR PANDA ${ }^{2}$, TAPASWINI MISHRA ${ }^{1}$
}

${ }^{1}$ Department of Physiology, Institute of Medical Sciences \& SUM Hospital, Bhubaneswar, Odisha, India. ${ }^{2}$ Department of Anatomy, Institute of Medical Sciences \& SUM Hospital, Bhubaneswar, Odisha, India. Email: purabipriyambada@gmail.com

Received: 03 April 2017, Revised and Accepted: 03 May 2017

ABSTRACT

Objective: Antioxidant probably can prevent the progression and complications of Type 2 diabetes mellitus (T2DM). Due to effectiveness of alpha lipoic acid (ALA) as an antioxidant, this study was done in T2DM patients to evaluate the effect of ALA on their diabetic status, lipid profile, and oxidative stress (OS) status.

Methods: A total of 35 patients with diabetes were selected randomly who were under insulin treatment mainly and grouped as Group "A." Another age- and sex-matched healthy controls selected grouped as "B." Both groups supplemented with ALA (300 mg/day) for 6 months continuously. All parameters were tested before and after the supplementation.

Results: There was a significant decrease in fasting blood sugar from 161 to $122 \mathrm{mg} / \mathrm{dl}$ in Group "A" and from 98 to 90 mg/dl in Group "B." Postprandial blood sugar (PPBS) and glycosylated hemoglobin (HbA1c) levels also significantly decreased from 211 to $158 \mathrm{mg} / \mathrm{dl}$ and $8.81 \%$ to $7.2 \%$, respectively, in Group "A." PPBS levels significantly decreased from 130 to $124 \mathrm{mg} / \mathrm{dl}$ in Group "B," but HbA1c\% decreased insignificantly from 5.26\% to 5.24\% in Group "B." Lipid profile parameters decreased in both groups except triglyceride level, which show insignificant relation in Group "B." OS marker malondialdehyde significantly decreased from 1.967 to $1.592 \mathrm{~nm} / \mathrm{ml}$ in Group "A" and from 0.613 to $0.472 \mathrm{~nm} / \mathrm{ml}$ in Group "B." Plasma antioxidant glutathione shows a significant increase in both groups from 2.117 to $2.405 \mu \mathrm{mol} / \mathrm{L}$ in Group "A" and from 2.631 to $2.811 \mu \mathrm{mol} / \mathrm{L}$ in Group "B." Plasma nitric oxide also shows significant increase in both groups from 1.712 to $1.990 \mu \mathrm{mol} / \mathrm{L}$ and from 2.139 to $2.318 \mu \mathrm{mol} / \mathrm{L}$, respectively.

Conclusion: Therefore, ALA is a potent antioxidant and can be used against oxidative injury associate with T2DM.

Keywords: Type 2 diabetes mellitus, Alpha lipoic acid, Oxidative stress markers.

(C) 2017 The Authors. Published by Innovare Academic Sciences Pvt Ltd. This is an open access article under the CC BY license (http://creativecommons. org/licenses/by/4. 0/) DOI: http://dx.doi.org/10.22159/ajpcr.2017.v10i8.18869

\section{INTRODUCTION}

As a chronic metabolic disorder, diabetes mellitus (DM) characterized by hyperglycemia due to defect in secretion or action of insulin or both, this causes imbalance in carbohydrate and fat metabolism [1]. DM is mainly categorized into Type 1 and Type 2. Type 1 DM (T1DM) is primarily due to autoimmune pancreatic $ß$-cell destruction. Type 2 DM (T2DM) is the frequent form and is due to impaired insulin secretion or insulin resistance [2]. According to the Diabetes Atlas 2011 , the incidence of diabetes is increasing and expected to reach from 366 million in 2011 to 552 million by 2030 [3]. Due to diversity of manifestation of disease and its complications, it causes a great human suffering physically, mentally, and even economically, even with the enormous available facilities to control the disorder [4]. In the disease progression, the prolonged exposure to hyperglycemia causes many long-term microvascular or macrovascular complications involving cardiovascular system, excretory system, nervous system causes diabetic cardiomyopathy, diabetic retinopathy, and neuropathy, which are prime cause of disability, morbidity, and premature death in T2DM $[5,6]$.

Oxidative stress (OS) results insulin resistance in T2DM [7]. Hence, number of studies done to know the effect of antioxidant supplementation in T2DM treatment, where some found positive result [8-10], while others found none [11]. Alpha lipoic acid (ALA) a both fat and water soluble antioxidant may help in regenerating other antioxidants and make them active again so often termed as "universal antioxidant." ALA might protect metabolic syndromes such as DM, improving insulin sensitivity and preventing distal sensory-motor diabetic neuropathy [12]. According to Blumenthal study, ALA in their experimental study improved the glycemic condition by acting on the liver [13]
However, there are some inconclusive evidences regarding its action in defending the OS level, improving the conditions of insulin deficiency and improvement of lipid profile level in T2DM patients. They are mostly done on animals $[14,15]$. As the T2DM incidence is increasing rapidly, the present study was undertaken to explore the effect of ALA supplementation on glycemic indexes, lipid profiles, and OS markers in T2DM patients.

\section{METHODS}

This was a prospective study including patients who were attending Endocrinology Department (both indoor and outdoor) and their biomolecular investigations were carried in Physiology Department and Biochemistry Department, IMS and SUM Hospital, Bhubaneswar. The institutional ethical committee approval was obtained.

For this study, 35 patients suffering from T2DM were included in Group "A," who were taking insulin as their main treatment. Moreover, 35 healthy participants were taken as controls, who were matched by age and gender, grouped as Group "B." The study protocol was explained to the patients, and their written consent was obtained. All patients were supplemented by ALA capsules (133 mg), 2 capsules/day for 6 months continuously.

- Inclusion criteria were patients with T2DM with fasting blood sugar (FBS) $<250 \mathrm{mg} / \mathrm{dl}$. Moreover, patients taking insulin as their main treatment

- Exclusion criteria: Patients with T2DM whose FBS $>250 \mathrm{mg} / \mathrm{dl}$; patients with uncontrolled hypertension (blood pressure $>140 / 90 \mathrm{mmHg}$ in spite of antihypertensive drugs); patients with complications of diabetes including nephropathy, retinopathy, and neuropathy; patients with any history of myocardial infarction or cardiac intervention or clinically active cardiovascular diseases; patients 
with known renal or hepatic diseases; and pregnant females, unwillingness to participate, or mental incapacity to take the drugs were excluded from the study.

A pro forma was designed to obtain basic demographic information taking data of weight and height. Their body mass index (BMI) was calculated using Quetelet's index by formula weight $/$ height $^{2}$ and expressed in $\mathrm{kg} / \mathrm{m}^{2}$. Blood samples collected for estimation of FBS, postprandial blood sugar (PPBS), glycosylated hemoglobin (HbA1c), lipid profile, and OS markers. FBS and PPBS were estimated by glucose oxidase method. HbA1c was calculated by cation exchange high-performance liquid chromatography using D-10-Hemoglobin Testing System (Bio-Rad). Lipid profiles were estimated using semiautoanalyzer, TRANSASIA, ERBA, and CHEM-5-PLUS. OS markers such as malondialdehyde (MDA), glutathione (GSH), and nitric oxide (NO) were measured using spectrophotometer.

Their baseline data and after 6 months supplementation data were compared among both groups. Statistical analysis was performed using Student's paired t-test using SPSS software 20 version, and $\mathrm{p}<0.05$ was considered statistically significant.

\section{RESULTS}

As shown in Table 1, there is non-significant difference in age, weight, and height of patients recruited in both groups, so they are matched by all these factors. We recruited 17 females and 18 males in Group A and 16 females and 19 males in Group B. Data are presented as mean \pm standard deviation from mean

Table 2 shows sugar levels such as FBS, PPBS, and HbA1c values at the initial stage of experiment. In the diabetic group, i.e., Group A has significantly more levels in comparison to Group B, where normal healthy controls were taken as control. As shown in Table 2, lowdensity lipoprotein (LDL), very LDL (VLDL), triglyceride (TG), and total cholesterol (TCh) levels were more and high-density lipoprotein (HDL) is less in diabetic group, Group A than healthy group, Group B. OS markers such as plasma GSH and NO levels are less and high MDA level in Group A in comparison to Group B.

Effects of administration of ALA on different parameters are shown in Table 3. It shows non-significant change of weight and BMI of both

Table 1: Demographic data of both groups

\begin{tabular}{lll}
\hline Parameters & Group A $(\mathbf{n}=\mathbf{3 5})$ & Group B $(\mathbf{n = 3 5})$ \\
\hline Age $($ years $)$ & $51.08 \pm 13.085$ & $48.60 \pm 12.23$ \\
Weight $(\mathrm{kg})$ & $60.914 \pm 9.546$ & $62.400 \pm 6.869$ \\
Height $(\mathrm{cm})$ & $158.685 \pm 6.430$ & $159.514 \pm 6.045$ \\
BMI $\left(\mathrm{kg} / \mathrm{m}^{2}\right)$ & $24.046 \pm 2.263$ & $24.505 \pm 2.111$ \\
\hline
\end{tabular}

Table 2: Baseline sugar levels, lipid profile levels of both groups

\begin{tabular}{lll}
\hline Parameters & Group A $(\mathbf{n = 3 5})$ & Group B $(\mathbf{n = 3 5})$ \\
\hline FBS $(\mathrm{mg} / \mathrm{dl})$ & $161.31 \pm 15.94^{*}$ & $98.05 \pm 12.59^{*}$ \\
PPBS $(\mathrm{mg} / \mathrm{dl})$ & $211.37 \pm 22.30^{*}$ & $130.02 \pm 12.87^{*}$ \\
HbA1c $(\%)$ & $8.81 \pm 1.07^{*}$ & $5.26 \pm 0.42^{*}$ \\
TCh $(\mathrm{mg} / \mathrm{dl})$ & $223.34 \pm 25.77^{*}$ & $147.22 \pm 14 .^{*} 83$ \\
TG $(\mathrm{mg} / \mathrm{dl})$ & $175.57 \pm 29.83^{*}$ & $128.22 \pm 20.48^{*}$ \\
HDL $(\mathrm{mg} / \mathrm{dl})$ & $36.60 \pm 4.50^{*}$ & $39.34 \pm 3.21^{*}$ \\
LDL $(\mathrm{mg} / \mathrm{d})$ & $161.85 \pm 19.60^{*}$ & $107.17 \pm 10.9^{*} 9$ \\
VLDL $(\mathrm{mg} / \mathrm{dl})$ & $36.88 \pm 6.77^{*}$ & $28.80 \pm 4.22^{*}$ \\
MDA $(\mathrm{nm} / \mathrm{ml})$ & $1.967 \pm 0.581^{*}$ & $0.613 \pm 0.368^{*}$ \\
GSH $(\mu \mathrm{mol} / \mathrm{L})$ & $2.117 \pm 0.749^{*}$ & $2.631 \pm 0.495^{*}$ \\
NO $(\mu \mathrm{mol} / \mathrm{L})$ & $1.712 \pm 0.427^{*}$ & $2.139 \pm 0.536^{*}$ \\
\hline
\end{tabular}

${ }^{*} \mathrm{p}<0.05$ : Significant. FBS: Fasting blood sugar, PPBS: Postprandial blood sugar, HbA1c: Glycosylated hemoglobin, TCh: Total cholesterol, TG: Triglyceride, HDL: High-density lipoprotein, LDL: Low-density lipoprotein, VLDL: Very low-density lipoprotein, MDA: Malondialdehyde, GSH: Glutathione, NO: Nitric oxide groups due to ALA effect. Sugar levels such as FBS and PPBS show a significant decrease after ALA supplement. HbA1c values show a significant decrease in Group A but non-significant decrease in Group B after ALA supplementation. Lipid profiles show a significant decrease in both groups due to ALA. OS shows significant decrease as shown by their markers in both groups due to ALA

\section{DISCUSSION}

As shown in Table 1, all patients were matched by age and gender, also by their height, weight, and BMI. The basal values of sugar levels show higher values in Group A, who were diabetics. Due to worsening of hyperglycemia condition overtime, progressive decrease in beta-cell function occurs [16]. This demands added medications such as insulin and other oral hypoglycemic drugs to control this blood sugar level [17]. However, as there is multifactorial pathogenesis to develop different complications in T2DM, monotherapy appears insufficient to deal with T2DM $[18,19]$.

ALA has antioxidant properties, can enhance glucose uptake in T2DM, and also can prevent $ß$-cell destruction in T1DM [20-24]. Results from this study indicate that oral ALA supplementation caused significant reduction in plasma FBS and PPBS levels in both groups. HbA1c level was significantly decreased in Group A, whereas a non-significant lowering of HbA1c level was seen in Group B. These data are in agreement with studies of Mazzone et al., 1984 [25]; Packer et al., 2001 [26]; Maritim et al., 2003 [27]; and Kandeil et al., 2011 [28]. Glucose uptake is increased due to ALA as it increases glucose transporter translocation to cell membranes [29,30]. According to Sasvari and Nyakas, 2003 [31] and Bitar et al., 2004 [32], ALA activates the pathway of insulin signaling, causes phosphorylation of insulin receptors, and on myocytes and adipocytes, it exerts insulin-like actions $[28,33]$.

Lipid profile levels show increased LDL, VLDL, TGs, and TCh levels in diabetic group, Group A in comparison to Group B. These results supported by other studies such as Monnier et al., 1995 [34]; AbdelAzim et al., 2002 [35]; Mazzone et al., 1984 [25]; Sheela and Augusti, 1992 [36]; and Sobenin et al., 1994 [37] studies. The abnormally high concentration of serum lipid profiles in T2DM is mainly a result of increased mobilization of free fatty acids from peripheral depots as insulin inhibits hormone-sensitive lipase, while glucagon and catecholamine enhance lipolysis [38,39].

Table 3 shows a significant lowering of LDL, VLDL, TG, and TCh levels and significant increase in HDL, the good cholesterol level after ALA treatment. These findings are in accordance with Kocak et al., 2000 [40]; Song et al., 2005 [41]; and Lee et al., 2005 [42]. Researchers reveal that ALA activates catabolism of cholesterol into simpler components for the eventual synthesis of steroid hormones [43].

As shown in Table 2, OS markers such as GSH and NO levels, which combat the OS, are at lower level in Group A than Group B. Similarly, MDA a product of lipid peroxidation is significantly more in Group A than Group B. In patients with diabetes, there is increased production of AGEs [28] and due to overgeneration of reactive oxygen species (ROS), causing an imbalance and produces OS [44]. GSH is a tripeptide present in all cells in micromolar concentrations has great antioxidative property $[45,46]$. Low levels of GSH in T2DM patients in our study are in accordance withfindings of other studies [47-51].

ß-oxidation of fatty acids initiated by increased activity of enzyme fatty acyl coenzyme A oxidase due to hypoinsulinemia results lipid peroxidation [52]. The products of lipid peroxidation such as MDA are harmful to most of body cells and are associated different disease conditions such as brain damage, micro- and macrovascular complications [53]

ALA has amphiphilic nature and reduces ROS in cell membrane as well as at their mitochondrial source level [53-56]. Inside cells and tissues, ALA is reduced to dihydrolipoic acid that is even more potent antioxidant. 
Table 3: Comparative analysis of changes in parameters before and after the supplementation of ALA in both groups

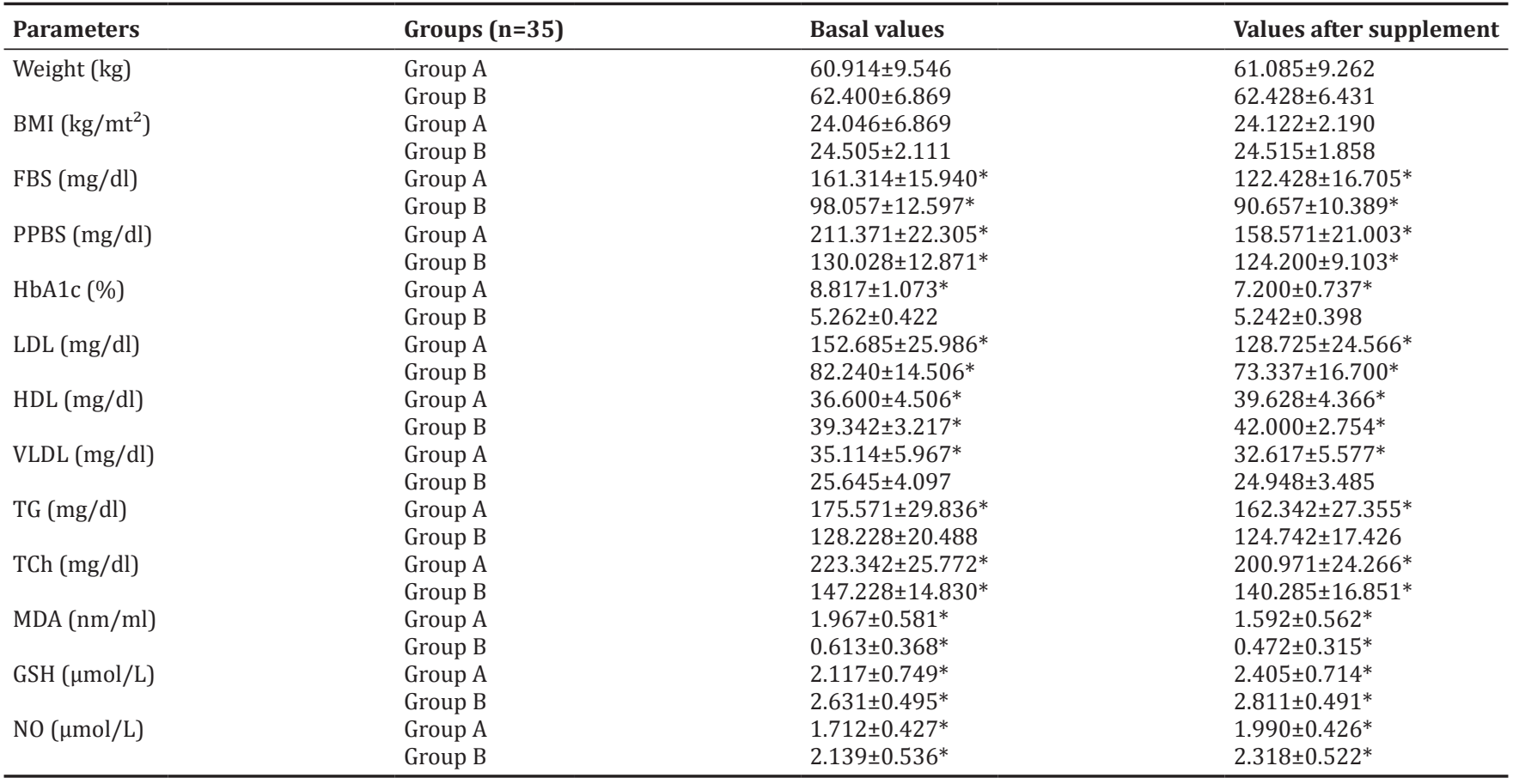

${ }^{*} \mathrm{p}<0.05$ : Significant. FBS: Fasting blood sugar, PPBS: Postprandial blood sugar, HbA1c: Glycosylated hemoglobin, TCh: Total cholesterol, TG: Triglyceride,

HDL: High-density lipoprotein, LDL: Low-density lipoprotein, VLDL: Very low-density lipoprotein, MDA: Malondialdehyde, GSH: Glutathione, NO: Nitric oxide, BMI: Body mass index, ALA: Alpha lipoic acid

Our results show after ALA supplementation OS levels were reduced, which support other studies [57-60].

\section{CONCLUSION}

Results obtained in our study indicate that the ALA can be used as an antioxidant in T2DM treatment along with the antidiabetic therapy to reduce different consequences as a result DM itself. ALA may be used to manage OS and dyslipidemic conditions developed due to hyperglycemic conditions in DM.

\section{ACKNOWLEDGMENT}

The authors would like to thank Dr. Kiran Dukhu (Professor and HOD); Dr. Pusparani Dash (Professor); and Dr Arati Mohanty (Professor) from Department of Physiology; Dr. Sudhanshu S. Mishra (Professor and HOD), Department of Pharmacology; IMS and SUM Hospital, Bhubaneswar, for their kind support.

\section{REFERENCES}

1. Arshpreet K, Shivangi S, Nancy T, Samiksha K, Shalini M. Current treatments for Type 2 diabetes, their side effects and possible complementary treatments. Int J Pharm Pharm Sci 2015;7(3):13-8.

2. Jayesh BD, Snehal NM, Archana RJ. Diabetic nephropathy - Genesis, prevention and treatment. Int J Pharm Pharm Sci 2014;6(9):42-7.

3. International Diabetes Federation. Diabetes Atlas. Belgium: International Diabetes Federation; 2011. p. 14.

4. Kuchake VG, Upasani CD. Effect of vitamin E and C plus reduced glutathione in treatment of diabetic nephropathy. Int J Pharm Pharm Res 2013;2(12):1-5.

5. Stancoven A, McGuire DK. Preventing macrovascular complications in Type 2 diabetes mellitus: Glucose control and beyond. Am J Cardiol 2007;99(IIA):5-11

6. Kaliamurthi S, Selvaraj G. Insight on solid lipid nanoparticles: Characterization and application in diabetes mellitus. J Crit Rev 2016;3(4):11-6.

7. Evans JL, Goldfine ID, Maddux BA, Grodsky GM. Are oxidative stress-activated signaling pathways mediators of insulin resistance and ß-cell dysfunction? Diabetes 2003;52(1):1-8.
8. Paolisso G, D'Amore A, Galzerano D, Balbi V, Giugliano D, Varricchio $\mathrm{M}$, et al. Daily vitamin E supplements improve metabolic control but not insulin secretion in elderly Type II diabetic patients. Diabetes Care 1993;16(11):1433-7.

9. Jacob S, Ruus P, Hermann R, Tritschler HJ, Maerker E, Renn W, et al. Oral administration of RAC-alpha-lipoic acid modulates insulin sensitivity in patients with Type 2 diabetes mellitus: A placebocontrolled pilot trial. Free Radic Biol Med 1999;27(3-4):309-14.

10. Akilandeswari V, Sekkizhar M, Santhakumari AS, Nirmala P. Nephroprotective effect of lycopene in hyperglycemia induced oxidative stress in male wistar rats. Int J Curr Pharm Res 2015;7(2):77-9.

11. Skrha J, Sindelka G, Kvasnicka J, Hilgertova J. Insulin action and fibrinolysis influenced by vitamin $\mathrm{E}$ in obese Type 2 diabetes mellitus. Diabetes Res Clin Pract 1999;44(4):27-33.

12. Packer L, Witt EH, Tritschler HJ. Alpha-lipoic acid as a biological antioxidant. Free Radic Biol Med 1995;19(2):227-50.

13. Blumenthal SA. Inhibition of gluconeogenesis in rat liver by lipoic acid. Evidence for more than one site of action. Biochem $\mathrm{J}$ 1984;219(3):773-80.

14. Amom Z, Zakaria Z, Mohamed J, Azlan A, Bahari H, Taufik HB, et al. Lipid lowering effect of antioxidant alpha-lipoic acid in experimental atherosclerosis. J Clin Biochem Nutr 2008;43(2):88-94.

15. Zulkhairi A, Zaiton Z, Jamaluddin M, Sharida F, Mohd TH, Hasnah B, et al. Alpha lipoic acid possess dual antioxidant and lipid lowering properties in atherosclerotic-induced New Zealand white rabbit. Biomed Pharmacother 2008;62(10):716-22

16. Del Prato S, Marchetti P. Beta- and alpha-cell dysfunction in Type 2 diabetes. Horm Metab Res 2004;36(11-12):775-81.

17. Duckworth WC. Hyperglycemia and cardiovascular disease. Curr Atheroscler Rep 2001;3(5):383-91.

18. Mathis D, Vence L, Benoist C. Beta-cell death during progression to diabetes. Nature 2001;414(6865):792-8.

19. Kant R, Ramesh B, Garima K, Rubina B. Development and validation of novel spectrophotometric methods for simultaneous estimation of pioglitazone and metformin in bulk and fixed dasage forms by area under curve and dual wavelength mode. Int J Appl Pharm 2016;8(3):48-53.

20. Evans JL, Goldfine ID. A-lipoic acid: A multifunctional antioxidant that improves insulin sensitivity in patients with Type 2 diabetes. Diabetes Technol Ther 2000;2(3):401-13.

21. Jacob S, Henriksen EJ, Schiemann AL, Simon I, Clancy DE, Tritschler HJ, et al. Enhancement of glucose disposal in patients 
with Type 2 diabetes by alpha-lipoic acid. Arzneimittelforschung $1995 ; 45(8): 872-4$

22. Borcea V, Nourooz-Zadeh J, Wolff SP, Klevesath M, Urich M, Peter W, et al. $\alpha$-lipoic acid decreases oxidative stress even in diabetic patients with poor glycemic control and albuminuria. Free Radic Biol Med 1999;26(11-12):1495-500.

23. Khamaisi M, Rudich A, Potashnik R, Tritschler HJ, Gutman A, Bashan N. Lipoic acid acutely induces hypoglycemia in fasting nondiabetic and diabetic rats. Metabolism 1999;48(4):504-10

24. Estrada DE, Ewart HS, Tsakiridis T, Volchuk A, Ramlal T, Tritschler H, et al. Stimulation of glucose uptake by the natural coenzyme $\alpha$-lipoic acid/thioctic acid: Participation of elements of the insulin signaling pathway. Diabetes 1996;45(12):1798-804.

25. Mazzone T, Foster D, Chait A. In vivo stimulation of low density lipoprotein degradation by insulin. Diabetes 1984;33(4):333-8.

26. Packer L, Kraemer K, Rimbach G. Molecular aspects of lipoic acid in the prevention of diabetes complications. Nutrition 2001;17(10):888-95.

27. Maritim AC, Sanders RA, Watkins JB $3^{\text {rd }}$. Effect of $\alpha$-lipoic acid on biomarkers of oxidative stress in streptozotocin-induced diabetic rats. J Nutr Biochem 2003;14(5):288-94.

28. Kandeil MA, Amin KA, Hassanin KA, Ali KM, Mohammed ET. Role of lipoic acid on insulin resistance and leptin in experimentally diabetic rats. J Diabetes Complications 2011;25(1):31-8.

29. Ansar H, Mazloom Z, Kazemi F, Hejezi N. Effect of alpha-lipoic acid on blood glucose, insulin resistance, and glutathione peroxidase of Type 2 diabetic patients. Saudi Med J 2011;32(6):584-8.

30. Konrad D. Utilization of the insulin-signaling network in the metabolic actions of alpha-lipoic acid-reduction or oxidation? Antioxid Redox Signal 2005;7(7-8):1032-9.

31. Sasvari M, Nyakas C. Time dependent changes in oxidative metabolism during chronic diabetes in rats. Acta Biol Szeged 2003;47(1-4):153-8.

32. Bitar MS, Wahid S, Pilcher CW, Al-Saleh E, Al-Mulla F. Alpha lipoic acid mitigates insulin resistance in Goto-Kakizaki rats. Horm Metab Res 2004;36(8):542-9.

33. Moini H, Packer L, Saris NE. Antioxidant and prooxidant activities of $\alpha$-lipoic acid and dihydrolipoic acid. Toxicol Appl Pharmacol 2002;182(1):84-90.

34. Monnier L, Colette C, Percheron C, Descomps B. Insulin, diabetes and cholesterol metabolism. C R Seances Soc Biol Fil 1995;189(5):919-31.

35. Abdel-Azim SA, Bader AM, Barakat MA. Effect of metformin, glyburide, and/or selenium on glucose homeostasis, lipid peroxidation, glutathione levels and changes in glutathione peroxidase activity in streptozotocin-induced diabetic rats. Egypt J Biochem 2002;20:393-411.

36. Sheela CG, Augusti KT. Antidiabetic effects of S-ally cysteine sulphoxide isolated from garlic Allium sativum Linn. Indian J Exp Biol 1992;30(6):523-6.

37. Sobenin IA, Tertov VV, Orekhov AN. Characterization of chemical composition of native and modified low-density lipoprotein occurring in the blood of diabetic patients. Int Angiol 1994;13(1):78-83.

38. Venkateswaran S, Pari L, Saravanan G. Effect of Phaseolus vulgaris on circulatory antioxidants and lipids in rats with streptozoticin induced diabetes. J Med Food 2002;5(2):97-103.

39. Suryawanshi NP, Bhutey AK, Nagdeote AN, Jadhav AA, Manoorkar GS. Study of lipid peroxide and lipid profile in diabetes mellitus. Indian J Clin Biochem 2006;21(1):126-30.

40. Kocak G, Aktan F, Canbolat O, Ozogul C, Elbeg S, Yildizoglu-Ari N, et al. Alpha-lipoic acid treatment ameliorates metabolic parameters, blood pressure, vascular reactivity and morphology of vessels already damaged by streptozotocin-diabetes. Diabetes Nutr Metab 2000;13(6):308-18.

41. Song KH, Lee WJ, Koh JM, Kim HS, Youn JY., Park HS, et al. Alphalipoic acid prevents diabetes mellitus in diabetes-prone obese rats. Biochem Biophys Res Commun 2005;326(1):197-202.

42. Lee WJ, Song KH, Koh EH, Won JC, Kim HS, Park HS, et al. $\alpha$-lipoic acid increases insulin sensitivity by activating AMPK in skeletal muscle. Biochem Biophys Res Commun 2005;332(3):885-91.

43. Woodhouse PR, Khaw K. Seasonal variations in vitamin C status, infection, fibrinogen and cardiovascular disease - Are they linked? Age Ageing 1994;23(2):5.

44. Aronson D. Cross-linking of glycated collagen in the pathogenesis of arterial and myocardial stiffening of aging and diabetes. J Hypertens 2003;21(1):3-12.

45. Lu SC. Regulation of hepatic glutathione synthesis: Current concepts and controversies. FASEB J 1999;13(10):1169-83.

46. Feng B, Yan XF, Xue JL, Xu L, Wang H. The protective effects of $\alpha$-lipoic acid on kidneys in Type 2 diabetic Goto-Kakisaki rats via reducing oxidative stress. Int J Mol Sci 2013;14(4):6746-56.

47. Ceriello A. Oxidative stress and glycemic regulation. Metabolism 2000;492 Suppl 1:27-9.

48. Giugliano D, Ceriello A, Paolisso G. Oxidative stress and diabetic vascular complications. Diabetes Care 1996;19(3):257-67.

49. Hughes K, Choo M, Kuperan P, Ong CN, Aw TC. Cardiovascular risk factors in non-insulin dependent diabetics compared to non-diabetic controls: A population based survey among Asians in Singapore. Atheroscler J 1998;136(1):25-31.

50. Jain SK, McVie R. Effect of glycemic control, race (white versus black) and duration of diabetes on reduced glutathione content in erythrocytes of diabetic patients. Metabolism 1994;43(3):306-9.

51. Oberley LW. Free radicals and diabetes. J Free Radic Biol Med 1988;5(2):113-24

52. Horie $\mathrm{S}$, Ishii $\mathrm{H}$, Suga $\mathrm{T}$. Changes in peroxisomal fatty acid oxidation in diabetic rat liver. J Biochem 1981;90(6):1691-6.

53. Acworth IN, Mccabe DR, Maher TJ. The analysis of free radicals, their reaction products, and antioxidants. In Baskin SI, Salem H, editors. Oxidants, Antioxidants and Free Radicals. Ch. 2. Washington, DC: Taylor and Francis; 1997.

54. Singh U, Jialal I. Alpha-lipoic acid supplementation and diabetes. Nutr Rev 2008;66(11):646-57.

55. American Diabetes Association. Diagnosis and classification of diabetes mellitus. Diabetes Care 2005;28 Suppl 1:S37-43.

56. Aragno M, Tamango E, Gatto V, Brignardello E, Parola S, Danni O, et al. Dehydroepiandrosterone protects tissues of streptozoticintreated rats against oxidative stress. Free Radic Biol Med 1999;26(1112):1467-74

57. Malarkodi KP, Sivaprasad R, Varalakshmi P. Effect of lipoic acid on the oxidoreductive status of red blood cells in rats subject to oxidative stress by chronic administration of adriamycin. Hum Exp Toxicol 2004;23(3):129-35.

58. Arambašić J, Mihailović M, Uskoković A, Dinić S, Grdović N, Marković J, et al. Alpha-lipoic acid upregulates antioxidant enzyme gene expression and enzymatic activity in diabetic rat kidneys through an O-GlcNAc-dependent mechanism. Eur J Nutr 2013;52(5):1461-73.

59. Becker BF. Towards the physiological function of uric acid. Free Radic Biol Med 1993;14(6):615-31.

60. Mcllduff CE, Rutkove SB. Critical appraisal of the use of alpha lipoic acid (thioctic acid) in the treatment of symptomatic diabetic polyneuropathy. Ther Clin Risk Manag 2011;7:377-85. 